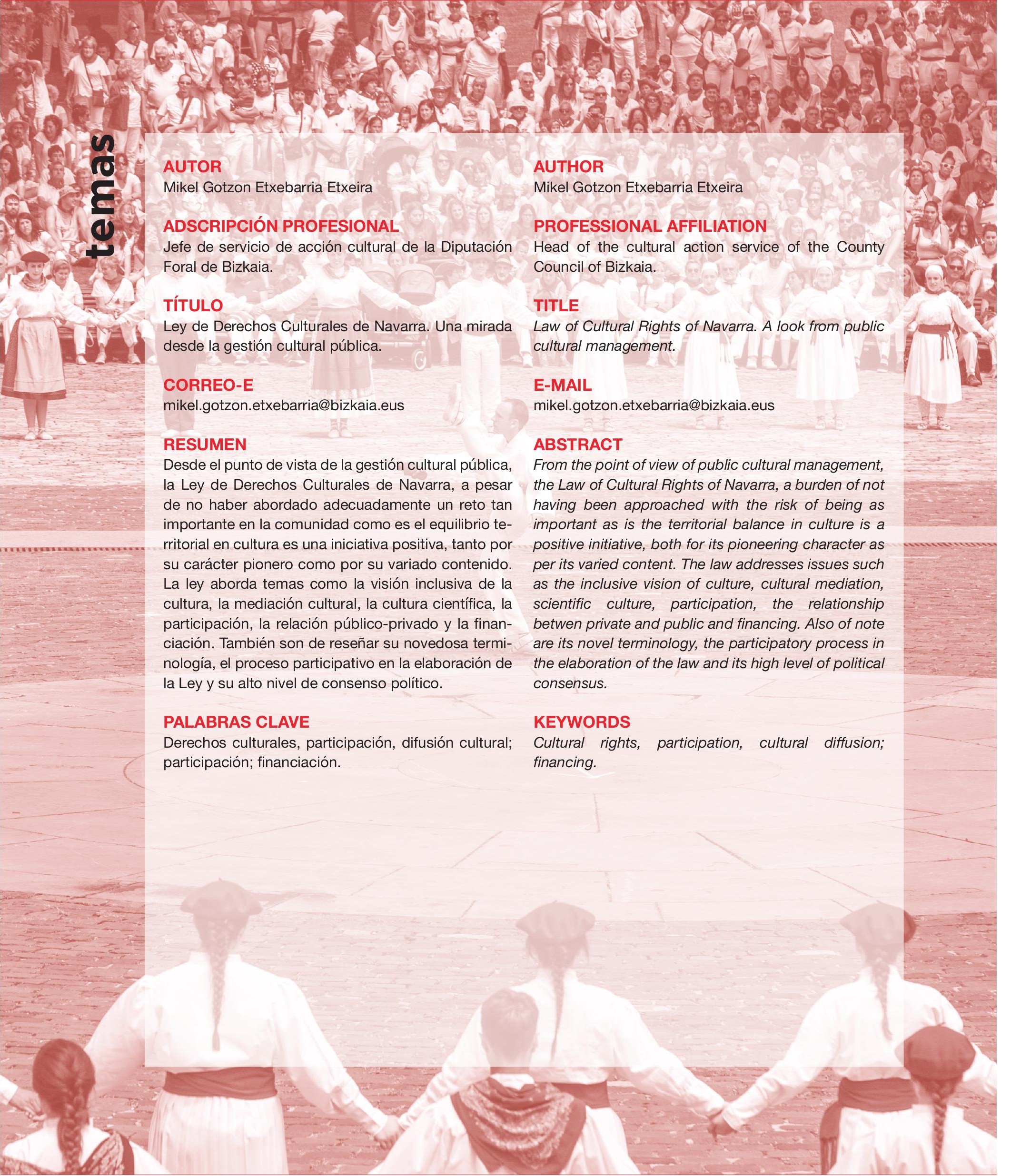




\section{Ley de Derechos Culturales de Navarra. Una mirada desde la gestión cultural pública}

\section{Mikel Gotzon Etxebarria Etxeita}

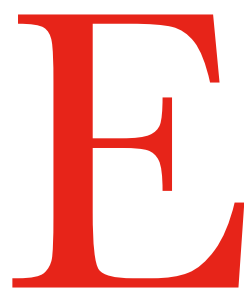

ste artículo tiene por objetivo plasmar las impresiones que la recién aprobada Ley de Derechos Culturales de Navarra genera en un gestor cultural público. No se trata por la tanto de un análisis jurídico sino de una mirada desde la gestión cultural pública.

Esta va a articularse en cuatro apartados:

\section{I.- Introducción}

II.- Proceso de elaboración

III.- Comentarios al texto

IV.- Consideraciones generales

\section{I.- Introducción}

Está de moda un discurso utilitarista de la cultura. Hay que invertir en cultura porque produce beneficios económicos y porque genera cohesión social, y para su legitimación se realizan estudios de impacto económico de los equipamientos y eventos culturales. Está bien pero no es todo. La rentabilidad social es importante y necesaria. El retorno económico es una cuestión a tener en cuenta, pero no pode- mos vivir bajo la dictadura del número. La inversión no se justifica exclusivamente por la audiencia. La visión economicista de la cultura no tiene un planteamiento sostenible hacia el sector cultural. La cultura genera retorno económico, pero desgraciadamente no vuelve al mundo de la misma.

La cultura es un derecho independientemente de sus utilidades y por ello es necesaria una ley de derechos culturales que asuma el papel de esta como el cuarto pilar de la sostenibilidad junto con la economía, la cohesión social y el medio ambiente, y garantice la cultura como una prestación más de los servicios públicos.

\section{II.- Proceso de elaboración}

Es de destacar el proceso participativo realizado de acuerdo con la Ley 39/2015 del Procedimiento Administrativo Común de las Administraciones Públicas, que plantea una doble consulta pública.

En la consulta previa se recogieron dos aportaciones de dos asociaciones profesionales (archiveros y gestores culturales). En la consulta con el anteproyecto elaborado se presentaron ocho alegaciones (cinco entidades y tres personas). 
Además, de manera complementaria el Departamento promotor realizó dos jornadas sobre el tema en octubre de 2017 y febrero de 2018 en las que participaron un total de 106 personas de entidades y organizaciones públicas y privadas del sector cultural.

Asimismo, es de destacar el alto nivel de consenso político conseguido en la tramitación del proyecto. La Ley se aprobó en el Parlamento de Navarra en el pleno del 11 de enero de 2019. Ha sido una Ley impulsada por el Gobierno Foral, liderado por Uxue Barkos y apoyado por el cuatripartito que ha sostenido el gobierno del cambio en la pasada legislatura 20152019 y que a pesar del complicado clima político de Navarra la Ley fue aprobada sin ningún voto en contra. Votaron a favor las agrupaciones políticas que apoyaban el Gobierno (Geroa Bai, EH Bildu, Podemos-Ahal Dugu-Orain Bai e Izquierda-Ezkerra), el PSN-PSOE y el PP de Navarra y se abstuvo UPN.

\section{III.- Comentarios al texto}

En este punto se van a recoger algunos contenidos de los diferentes apartados de la Ley que se consideran interesantes, sin voluntad de hacer un análisis del articulado de la misma.

\section{Preámbulo}

A la hora de la redacción de la Ley se realiza una invocación a la Declaración de Derechos Humanos de 1948 y al Pacto Internacional de Derechos Económicos, Sociales y Culturales de 1966, además de citar otras declaraciones y manifiesto, así como al artículo 44 de la Constitución Española que establece que los poderes públicos promoverán y tutelarán el acceso a la cultura, a la que todos tienen derecho.

Introduce el término de diversidad cultural; plantea la cultura como un bien común, transita del derecho a la cultura a los derechos culturales e introduce el término de «ecosistema cultural».

\section{Título I.- Disposiciones generales}

Fundamenta los derechos culturales en una base amplia, inclusiva y moderna con terminología adecuada. (Art. 4.1).

Aborda el tema de las identidades culturales y pertenencia a comunidades culturales.

Título II.- Derecho de acceso a la cultura y a la participación en la vida cultural

Es el título más extenso de la Ley y en él se trata básicamente del derecho al acceso de la cultura, en el que se incluye el «acceso físico, psíquico y sensorial» y se tiene en cuenta la diversidad lingüística.

Apuesta por la creación de un portal digital de la Cultura Navarra como un elemento importante en favor de la accesibilidad. En esa apuesta por la accesibilidad reconoce y pone en valor el papel de la mediación.

Es interesante su apuesta clara y fuerte en favor del acceso público a los BIC de Navarra, con especial incidencia en los de propiedad privada, bienes eclesiásticos incluidos, en los que se apuesta por favorecer la apertura al público de los mismos o por su depósito, si fuera posible, en instituciones públicas adecuadas para ello. Asimismo, y dentro de esa jugada por el acceso público a los museos y colecciones privadas, se plantea que esa accesibilidad será un criterio para la concesión de subvenciones (Artículo 13).

Para facilitar la accesibilidad, se apoya la digitalización de la documentación privada y del patrimonio bibliográfico, y su exhibición en el Portal Digital de la Cultura Navarra.

En lo referente a lo audiovisual, la Ley define las labores de la Filmoteca Navarra

En relación con las artes escénicas y a la música es de destacar el compromiso de fomentar la participación de los sectores profesionales y amateurs de las artes escénicas en la elaboración de las políticas culturales. (Artículo 16.a), de velar por el aumento del «reconocimiento y el prestigio social de las artes escénicas y de la música» (Artículo 16.b) y de fomentar el asociacionismo sectorial.

En este título también se habla de la participación y se definen dos campos. Por un lado, defiende la libre participación de las personas en la vida cultural de la comunidad eligiendo libremente la cultura de la comunidad que quieran, qué prácticas culturales quiere desarrollar y en qué idioma (Artículo 19). Por otro lado, reafirma el derecho a la participación a la hora de la toma de decisiones relacionadas con las políticas culturales publicas tanto individual como asociativamente.

\section{Título III.- Creación artística y literaria e investiga- ción científica \\ Mediante este título se incluye a la investigación cien-} tífica en el ámbito de la Ley y realiza una declaración programática de derechos que, aunque parezcan evidentes, no suelen ser contemplados de forma concreta y específica en los textos legales. Concretamente se refiere a los derechos de creación artística y literaria, a los de libertad de investigación científica, al de disfrutar de los beneficios del progreso cien- 


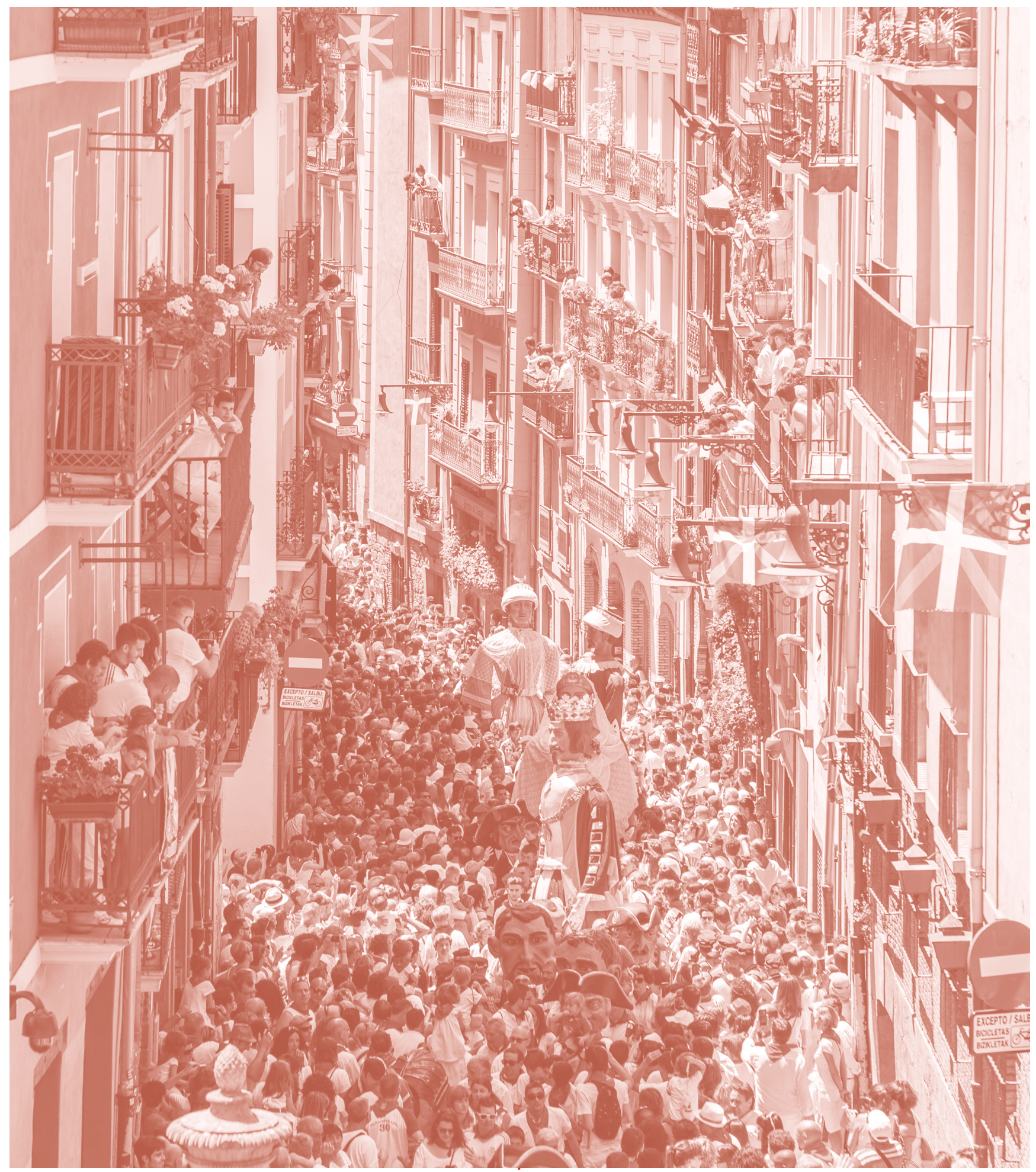


tífico y también hace una mención genérica a los derechos de autor.

Es de reseñar la mención al de las personas dedicadas a la creación cultural a un tratamiento fiscal razonable en base a las características especiales del trabajo en el sector cultural, como son la irregularidad e intermitencia de ingresos así como la complementariedad con otras actividades.

Título IV.- Responsabilidad de las administraciones públicas en materia de cultura

En este título se engloban las obligaciones que las administraciones navarras asumen con la aprobación de la Ley.

El Gobierno de Navarra, a través de su departamento competente en cultura básicamente se compromete a:

Dotarse de un código de buenas prácticas

Apostar en su labor editorial por los principios de cultura libre y procomún

Impulsar la profesionalización de los sectores culturales promoviendo medidas que garanticen los puestos propios de los sectores.

Colaborar con el departamento competente en educación, fortaleciendo y ampliando las enseñanzas artísticas y culturales en el sistema educativo, así como reforzando el papel de la cultura en el ámbito de la educación.

Promover la participación de las personas creadoras y sectores culturales en la definición de las políticas públicas, su desarrollo, aplicación y evaluación.

Impulsar un foro de coordinación y corresponsabilidad con los municipios.

Creación de foros o mesas de trabajo con los diferentes sectores.

Por otro lado, también define de forma general las competencias de los municipios. Es de reseñar la mención que realiza al tema de la cesión de espacios ya que en su artículo 34. 4 textualmente indica: «Las Administraciones Públicas de Navarra fomentarán el uso creativo y cultural para los espacios en desuso y la innovación en modelos de gestión, incluida la cogestión y la autogestión».

Título V.- El Consejo Navarro de la Cultura y las Artes

Mediante este título, la Ley reforma el actual Consejo Navarro de la Cultura y le da rango (antes era un decreto), aunque sigue manteniendo su carácter consultivo. Dentro de sus funciones son de reseñar las siguientes:

Seguimiento y evaluación del Plan Estratégico de la Cultura de Navarra y de los planes de acción del departamento competente en cultura

Recibir información sobre el proceso de elaboración del proyecto de presupuestos del departamento competente en materia de cultura y de su ejecución.

\section{Título VI.- Disposiciones financieras y tributarias.}

A la hora de definir la financiación de las políticas culturales se aboga por un crédito presupuestario adecuado aproximándose a la media de las regiones europeas que se asemejan a la Comunidad Foral de Navarra, pero sin mayor concreción. Menciona específicamente la voluntad de fomentar el micro mecenazgo y de crear fondos que faciliten el crédito a las micro y pequeñas empresas de los sectores culturales.

\section{IV.- Consideraciones generales}

Es una ley pionera en el Estado. Ha habido algunos otros intentos pero no han cristalizado en un texto legal específicamente dedicado a los derechos culturales.

Es de reseñar el importante nivel de consenso político logrado (ningún partido en contra, seis a favor y una abstención).

Es una ley que impone una serie de obligaciones de desarrollo al Gobierno:

Código de buenas prácticas (Art. 30).

Uso de licencias que incorporen los fundamentos del

Copyfarleft (Art. 31).

Cartas de servicios del departamento en 1 año (Disposición adicional única).

Se nota que en su elaboración han participado personas vinculadas a la gestión cultural, entre otras razones por la apuesta por el reconocimiento de la profesionalización de los sectores culturales para los que demanda garantizar el reconocimiento de los puestos propio de los sectores (Artículo 32), y también por la incorporación de terminología específica vinculada a la gestión cultural y que raramente aparece en los textos legales. A modo de ejemplo son de reseñar los siguientes términos que aparecen en la Ley: diversidad cultural (Art. 2), mediación cultural (Art. 9), ecosistema cultural y 
creativo (Art.17), prototipos culturales (Art. 17), mapeos en el territorio (Art. 17), dimensión económica, tecnológica cultural y social de la cultura (Art. 17), Cultura Libre y Procomún, Copyfarleft (Art. 17), evaluación de impacto (Art. 33), y cogestión y autogestión (Art. 34).

Pone en valor la mediación cultural como elemento básico para el acceso del público al conocimiento de los códigos culturales de la creación artística.

Apuesta por una visión inclusiva de la cultura al mencionar la necesidad de garantizar el acceso físico, psíquico y sensorial a los equipamientos culturales (Artículo 7).

Apuesta por la difusión mediante la creación del Portal Digital de la Cultura Navarra.

Define derechos culturales básicos: libertad de creación, libertad lingüística, elección de cultura y de pertenencia a una comunidad.

Incorpora nuevos temas como el de la cultura científica aunque no lo desarrolla sino que solamente define derechos (libertad y disfrute).

Incluye de forma expresa, con un nivel de desarrollo y asunción de obligaciones, el tema de la participación y la colaboración público/privada:

Creación del Consejo Navarro de la Cultura y las Artes.

Fomento del asociacionismo sectorial en cultura.

Creación del Foro de Cooperación y Corresponsabilidad con los municipios.

La Ley es atrevida, ya que fomenta el uso creativo y cultural de los espacios en desuso y admite expresamente la cogestión y la autogestión como innovadores modelos de gestión de dichos espacios. Es un tanto prolija o descompensada hacia la accesibilidad del Patrimonio Cultural sobre todo del privado al que le dedica una parte importante del texto legal.

Con relación a la financiación, que es positivo que aparezca como un título propio en la misma, adopta una postura voluntarista ya que no fija un porcentaje sobre los presupuestos de la Comunidad Foral Navarra, sino que ha- bla de financiación adecuada y aproximada a la media de las regiones europeas que se asemejan a Navarra pero sin definirlas.

Sin embargo, es positiva su voluntad de apoyar a las micro y pequeñas empresas de los sectores culturales mediante la creación de fondos u otros instrumentos financieros, así como su apuesta por el micromecenazgo. En este sentido es de reseñar la Ley Foral 8/2014, de 16 de mayo, reguladora del mecenazgo cultural y de sus incentivos fiscales en la Comunidad Foral de Navarra (Boletín Oficial de Navarra de 26 mayo 2014) que hace una decidida apuesta por el micromecenazgo con aportaciones novedosas como la posibilidad de donaciones directas a artistas o la posibilidad de que desde la sociedad civil se puedan proponer actividades culturales para que la ciudadanía pueda elegir libremente la actividad de la cual ser mecenas.

También es de reseñar que la Ley reivindica en su artículo 24

el derecho a ser tratadas fiscalmente de forma razonable, ecuánime y equitativa atendiendo a la irregularidad y naturaleza intermitente de sus ingresos así como a su carácter complementario de otras actividades profesionales o económicas

La Ley, en mi opinión, presenta una carencia importante sobre todo teniendo en cuenta la realidad geográfica y demográfica de Navarra: no aborda de forma decidida y con medidas concretas el equilibrio territorial en cultura, ni plantea un mapa de equipamientos y servicios culturales en el territorio.

A modo de resumen, opino que es una iniciativa positiva, tanto por su carácter pionero, como por su contenido, su terminología y su alto nivel de consenso político. Esperemos que otras Comunidades Autónomas o el propio Estado se animen a legislar sobre los derechos culturales. 